\title{
ENSINO DE BIOLOGIA NA EDUCAÇÃO DE JOVENS E ADULTOS - PROBLEMATIZAÇÕES E FOCOS TEMÁTICOS DA PRODUÇÃO CIENTÍFICA BRASILEIRA (1996 - 2015)
}

\author{
TEACHING BIOLOGY IN YOUTH AND ADULT EDUCATION - \\ PROBLEMATIZATIONS AND THEMATIC FOCUSES OF BRAZILIAN SCIENTIFIC \\ PRODUCTION (1996 - 2015)
}

\begin{abstract}
ENSEÑANZA DE LA BIOLOGÍA EN LA EDUCACIÓN JUVENIL Y ADULTA PROBLEMATIZACIONES Y ENFOQUES TEMÁTICOS DE LA PRODUCCIÓN CIENTÍFICA BRASILEÑA (1996 - 2015)
\end{abstract}

Rones de Deus Paranhos

E-mail: paranhos@ufg.br Universidade Federal de Goiás - UFG

Maria Helena da Silva Carneiro

E-mail: mhsilcar@unb.br Universidade de Brasília - UnB

\begin{abstract}
RESUMO
Este estudo é um Estado da Arte que analisa artigos (28), dissertações (54) e teses (2) sobre o ensino de biologia na educação de jovens e adultos (EJA) e caracteriza essa produção a partir da seguinte questão: O problema e foco temático são determinações da atividade científica, portanto, quais são os traços estilísticos que caracterizam a produção científica sobre o ensino de biologia na EJA? Categorias da epistemologia fleckiana (Estilo de Pensamento - EP -, Círculo Esotérico - CEso - e Exotérico - CExo -) fundamentam as análises e indicam destaque para o foco temático Ensino (70,3\%), atividades do CExo (leigos formados). Os mestrados profissionais foram determinantes para a centralidade dada ao foco em seus aspectos metodológicos. O estudo aponta a necessidade do Coletivo de Pesquisadores Educação em Ciências (CPEC) considerar: i) aspectos políticopedagógicos do projeto formativo institucionalizado para o mestrado/doutorado profissional; ii) ampliação de pesquisas sobre as atividades do CExo dos leigos (educandos da EJA); iii) desenvolvimento de pesquisas sobre a atividade do CEso (especialistas) que se ocupam de investigações sobre ensino de física e química na EJA; iv) necessidade de o CPEC discutir as contribuições de artigos (Relato de Experiência) para o desenvolvimento do EP Educação em Ciências.
\end{abstract}

PALAVRAS-CHAVE: Educação em Ciências. EJA. Estado da Arte.

\section{ABSTRACT}

This study is a state of the art analysis of articles (28), dissertations (54) and theses (2) about the teaching of biology in youth and adult education (YAE). If the problem and thematic focus are determined by scientific activity, what are the stylistic traits that characterize scientific production on the teaching of biology in YAE? Categories of the Fleckian epistemology (Thinking Style - EP -, Esoteric Circle - CEso - and Exoteric - CExo -) support the analysis and highlight the thematic focus Teaching (70.3\%), activities of CExo. Professional masters were crucial 
for the centrality given to the focus on their methodological aspects. This study identifies the need for the Science Education Researchers Collective (CPEC) to consider: i) political-pedagogical aspect of the institutionalized formative project for the professional master / doctorate; ii) expansion of research on the activities of the lax CExo (EJA learners); iii) development of research on CESo's activity (specialists) that deals with research on physics and chemistry teaching in EJA; iv) the need for CPEC to discuss the contributions of articles (Experience Report) towards the development of EP Science Education.

KEYWORDS: Science Education. YAE. State of the Art.

\section{RESUMEN}

Este estudio es un estado del arte que analiza artículos (28), disertaciones (54) y tesis (2) sobre la enseñanza de la biología en la educación de jóvenes y adultos (EJA) y caracteriza esta producción en base a la siguiente pregunta: El problema y El enfoque temático son las determinaciones de la actividad científica, entonces, ¿cuáles son los rasgos estilísticos que caracterizan la producción científica en la enseñanza de la biología en EJA? Las categorías de epistemología fleckiana (Estilo de pensamiento - EP -, Círculo esotérico - CEso - y Exotérico CExo -) apoyan los análisis e indican el enfoque en el enfoque temático en la enseñanza (70.3\%), las actividades de CExo (graduados legos). Los másters profesionales fueron decisivos para la centralidad dada al enfoque en sus aspectos metodológicos. El estudio señala la necesidad de que el Colectivo de Investigadores en Educación en Ciencias (CPEC) considere: i) aspectos político-pedagógicos del proyecto de capacitación institucionalizada para el máster / doctorado profesional; ii) expansión de la investigación sobre las actividades del CExo de los laicos (estudiantes de EJA); iii) desarrollo de investigaciones sobre la actividad de CEso (especialistas) que se ocupan de la investigación sobre la enseñanza de la fisica y la química en EJA; iv) la necesidad de que el CPEC discuta las contribuciones de los artículos (Informe de experiencia) para el desarrollo de la Educación del PE en Ciencias.

PALABRAS-CLAVE: Enseñanza de las ciencias. EJA. Estado del Arte.

\section{INTRODUÇÃO}

O estudo ora apresentado é fruto de uma pesquisa de doutorado ${ }^{1}$ e o conteúdo deste artigo provocará a discussão da Educação de Jovens e Adultos (EJA) no campo de investigação da Educação em Ciências no Brasil. Sobretudo, porque toma para análise a produção científica - artigos, dissertações, teses - delimitando-se ao ensino de biologia na EJA, no período de 1996 a 2015.

A começar pelo recorte de tempo, há 24 anos a EJA foi institucionalizada pela Lei $\mathrm{n}^{\circ}$ 9.394/96 (Brasil, 1996), como modalidade da educação básica brasileira. Nesse interstício estabeleceu-se uma luta, seja pelos movimentos sociais e/ou pela produção científica do campo da $\mathrm{EJA}^{2}$, para defender uma educação de jovens e adultos a partir da concepção de educação como direito. Esse posicionamento de natureza política, em seu sentido latu, busca romper com as concepções assistencialistas de educação de adultos que imperaram nos idos das décadas 1960, 1970 e 1980, muito embora, ainda apresente elementos de permanência em textos de

\footnotetext{
${ }^{1}$ Programa de Pós-Graduação em Educação, Faculdade de Educação - Universidade de Brasília (PPGE-FE/UnB).

${ }^{2}$ Há de se destacar o papel dos fóruns estaduais de educação de jovens e adultos que constituem o Fórum EJA Brasil (http://www.forumeja.org.br/) e o grupo de trabalho de EJA (GT18) da Associação Nacional de PósGraduação e Pesquisa em Educação (ANPEd) nessa defesa.
} 
programas de governo, políticas públicas e práticas pedagógicas desenvolvidas nas redes municipais, estaduais e federais de ensino.

$\mathrm{Na}$ concepção assistencialista predomina o ideário de uma formação compensatória, aligeirada e de qualidade questionável para a correção de fluxo escolar do(a) educando(a). Por outro lado, a concepção de educação como direito não se reduz à garantia de acesso à escola, mas se amplia com o entendimento que os educandos da EJA têm o direito de se apropriar dos conceitos advindos de todas as áreas, dentre elas as ciências da natureza, tendo em vista uma leitura da realidade de modo mais complexo. Portanto, a concepção de educação como direito desenha para a educação escolar uma função muito específica, a de promover a socialização dos conhecimentos científicos produzidos historicamente pela atividade humana (PARANHOS; CARNEIRO, 2019a).

Para analisar a produção científica neste artigo, foram empregadas as ideias de Fleck $\left(2008^{3}\right)$, sobretudo, as que se vinculam aos conceitos de Coletivo de Pensamento (CP) e Estilo de Pensamento (EP). A partir da análise da atividade científica em torno da sífilis, Fleck elaborou esses conceitos e afirmou

Se definimos um coletivo de pensamento como a comunidade de pessoas que trocam ideias ou que interagem intelectualmente, então temos nele um vetor do desenvolvimento histórico de um domínio do pensamento, de um estado determinado do saber e de um estado da cultura, quer dizer de um estilo de pensamento particular (FLECK, 2008, p. 74, tradução nossa) ${ }^{4}$.

A definição demarca a relação entre CP e o EP. O primeiro, coloca em relevo a característica social da atividade científica, pois nela estão presentes a circulação de ideias e as interações intelectuais (FLECK, 2008) que se dão entre as pessoas. Para Fleck (2008, p. 79) os conhecimentos no $\mathrm{CP}$ “[...] circulent à l'intérieur de la communauté, sont taillées, transformées, renforcées ou affaiblies, influencent d'autres connaissances, l'élaboration de concepts, de conceptions et d'habitudes de pensée". Portanto, há uma circulação de pensamento (Circulation de Pensée) entre os membros de um coletivo. Há um vínculo entre o EP e as ideias,

\footnotetext{
${ }^{3}$ Fleck publicou o livro Entstehung und Entwicklung einer wissenschaftlichen (1935) traduzido para as línguas portuguesa - Gênese e desenvolvimento de um fato cientifico (2010) -; francesa - Genèse et développement d'un fait scientifique (2008) e espanhola - La génesis y el desarollo de un hecho cientifico (1986) -. Após uma leitura sistemática realizada em um grupo de estudos para comparar as traduções, este trabalho emprega a tradução francesa.

${ }^{4}$ Si nous définissons un collectif de pensée comme la communauté des personnes qui échangent des idées ou qui interagissent intellectuellement, alors nous tenons en lui le vecteur du développement historique d'un domaine de pensée, d'un état du savoir déterminé et d'un état de la culture, c'est-à-dire d'un style de pensée particulier (FLECK, 2008, p. 74).

${ }^{5}$ [...] circulam no interior da comunidade, são moldados, transformados, reforçados ou fragilizados, influenciam outros conhecimentos, a elaboração de conceitos, de concepções e de hábitos de pensamento (FLECK, 2008, tradução nossa)
} 
conceitos e concepções, dado que o EP os determina e estes, por sua vez, são compartilhados pelo EP dos coletivos. Um EP não é rígido, sendo-lhe possível o desenvolvimento, na medida que é compartilhado entre diferentes indivíduos de um coletivo. Na acepção fleckiana, conhecer alguma coisa não se desvincula de um modo de pensar posto numa determinada época e $\mathrm{CP}$, ou seja, há o entendimento de que a ciência é historicamente localizada.

O presente estudo emprega a compreensão de que os modos de pensar e fazer ciência (Fleck, 2008); o conjunto de práticas e conhecimentos comuns aos integrantes de um coletivo de pensamento (Lorenzetti, 2008); os modos de conceber os problemas utilizando teorias, metodologias e estilos de resoluções de problemas postos num grupo (Carneiro, 2012), são elementos constitutivos de um Estilo de Pensamento (EP). Com base nesses posicionamentos foram elencados e analisados os problemas e os focos temáticos da produção científica sobre o ensino de biologia na EJA. A partir do que expõe Fleck (2008) sobre os círculos esotéricos e exotéricos e das interpretações de Delizoicov (2002; 2004) e Slongo (2004), entende-se que os professores de ciências e seus alunos constituem, em relação ao Coletivo de Pesquisadores Educação em Ciências (CPEC), dois círculos exotéricos (leigos formados e leigos).

Fleck (2008) afirma que os coletivos de pensamento estáveis apresentam características estruturais (structurelles) comuns, as quais ele denominou de Círculo Esotérico (CEso) e Círculo Exotérico (CExo). O primeiro, menor, corresponde ao agrupamento de indivíduos pertencentes a um EP e/ou que foram iniciados nele. Entende-se, portanto, que os indivíduos que estão no CEso se apropriaram das conexões ativas desse estilo e estão diretamente envolvidos com a formação do pensamento do EP. O segundo é constituído por um número maior (plus large) de indivíduos e, esses por sua vez, não estão envolvidos diretamente com a formação do pensamento de determinado EP.

Desse apontamento depreende-se a compreensão de que o CEso é constituído pelos integrantes já iniciados a um EP ligado a um CP, portam a linguagem específica empregada no EP e "participam de polêmicas conceituais e deliberações às quais os demais membros do coletivo não possuem acesso" (CARNEIRO, 2012, p. 81). Brandão (2015, p. 61) compreende que a atividade do CEso está relacionada diretamente com a produção de conhecimento ou, como nas palavras da autora, são os "genitores de teorias", enquanto os integrantes do CExo são “os consumidores das ideias geradas”. Na mesma direção, estão Lambach e Marques (2009, p. 223) ao apontarem que o CEso é formado pelos pesquisadores, especialistas, cientistas e iniciados, ou seja, pelo que os autores chamam de "formuladores do conhecimento", enquanto, 
no CExo encontram-se os indivíduos que assimilam e consomem os conhecimentos produzidos pelo CEso. Delizoicov et al. (1999) entendem que os integrantes do CExo também participam do saber científico, contudo, o acesso se dá via uma linguagem mais simplificada.

As categorias Círculo Esotérico e Círculo Exotérico são relacionais. Na escola acontece a socialização dos conhecimentos das ciências de referência (biologia, física e química) que foram produzidos pelos círculos esotéricos (especialistas), mediatizados na educação escolar, por um círculo exotérico (professores de ciências - leigos formados) que ensina as ciências aos alunos da educação básica (leigos) (DELIZOICOV, 2004). Para Slongo e Delizoicov (2006), Muenchen e Delizoicov (2009), os professores de ciências são parte de um CExo, enquanto os alunos destes professores constituem outro CExo, em relação aos pesquisadores do Coletivo de Pesquisadores Educação em Ciências.

A partir do exposto, o objetivo deste estudo é caracterizar a produção científica brasileira - artigos, dissertações, teses - (1996-2015) que tomou como objeto de estudo o ensino de biologia na EJA para explicitar os traços estilísticos dessa produção a partir da análise dos problemas e focos temáticos. A distribuição dessa produção científica e os aspectos que despertaram o interesse intelectual de um coletivo de pesquisadores para investigar o ensino de biologia na EJA, são encontrados no trabalho de Paranhos e Carneiro (2019b).

\section{METODOLOGIA}

A pesquisa apresentada se identifica como um estudo do tipo Estado da Arte (Ferreira, 2002; Romanowski; Ens, 2006), pois inventaria e discute a produção científica (artigos, dissertações e teses) sobre o ensino de biologia na EJA. O corpus de análise (matriz empírica) foi constituído em dois momentos, um para a busca de artigos e outro para as dissertações e teses, conforme indica o Quadro 1.

Quadro 1 - Critérios estabelecidos para a constituição da matriz empírica da pesquisa.

\begin{tabular}{|c|c|}
\hline \multicolumn{2}{|c|}{ Artigos Científicos* } \\
\hline Periódicos (Qualis) & A1 a B2 \\
\hline Campo & $\begin{array}{c}\text { Educação em Ciências } \\
1996-2015\end{array}$ \\
\hline Período & $\begin{array}{c}\text { ensino de ciências, ensino de biologia na relação com a educação de } \\
\text { jovens e adultos, EJA, educação de adultos, podendo estes estarem } \\
\text { presentes no título, resumo e/ou palavras-chave do artigo. }\end{array}$ \\
\hline Descritores & Portal de Periódicos CAPES; Sites das revistas de educação em ciências \\
\hline Fonte de Dados
\end{tabular}




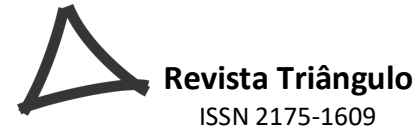

ISSN 2175-1609

\begin{tabular}{|c|c|c|c|}
\hline \multicolumn{4}{|r|}{ Dissertações e Teses* } \\
\hline \multirow{4}{*}{ 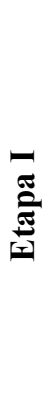 } & \multirow{4}{*}{ 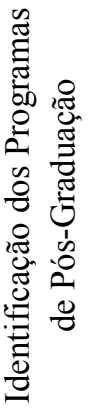 } & Área de Avaliação & Educação $^{6}$ e Ensino ${ }^{7}$ \\
\hline & & Período & $1996-2015$ \\
\hline & & Situação & Em funcionamento \\
\hline & & Área Básica & $\begin{array}{c}\text { Educação, Ensino-Aprendizagem, Educação de Adultos, Ensino e } \\
\text { Ensino de Ciências e Matemática }\end{array}$ \\
\hline \multirow{3}{*}{$\underset{\underset{\pi}{\pi}}{\stackrel{a}{\pi}}$} & \multirow{3}{*}{ 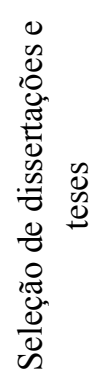 } & Período & $1996-2015$ \\
\hline & & Descritores & $\begin{array}{l}\text { ensino de ciências, ensino de biologia na relação com a educação de } \\
\text { jovens e adultos, EJA, educação de adultos, podendo estes estarem } \\
\text { presentes no título, resumo e/ou palavras-chave }\end{array}$ \\
\hline & & Bancos & $\begin{array}{l}\text { Plataforma Sucupira, Sites de Programas de Pós-Graduação (Educação e } \\
\text { Ensino), Banco de Teses de Dissertações de IES, Centro de } \\
\text { Documentação em Ensino de Ciências da Universidade de Campinas } \\
\text { (CEDOC - UNICAMP) }\end{array}$ \\
\hline
\end{tabular}

Fonte: Adaptado de Paranhos e Carneiro (2019b). * Todos os trabalhos levantados por este estudo foram lidos na íntegra.

\section{RESULTADOS E DISCUSSÃO}

\section{Problema e Foco Temático da Produção Científica}

A partir dos critérios explicitados na metodologia, foram encontrados 84 trabalhos distribuídos em 28 artigos, 54 dissertações e 2 teses. Tomando por base os problemas de pesquisas sobre ensino de biologia e as categorias epistemológicas CEso (Círculo Esotérico) e CExo (Círculo Exotérico), Slongo (2004) em seu estudo, propôs três tipificações para a análise das pesquisas, sendo elas: a) Pesquisas relativas às atividades do CExo dos leigos formados (professores formados); b) Pesquisas relativas às atividades do CExo dos leigos (alunos); c) Pesquisas relativas à dinâmica de interação entre ambos (professores e alunos). Neste artigo foi empregado a tipificação "a" e "b” para análise da produção científica.

\footnotetext{
${ }^{6}$ Para a escolha dos programas em Educação, os sites destes foram consultados para identificar as linhas de pesquisas. Aqueles que apresentavam em suas linhas a possibilidade do desenvolvimento de estudos sobre o ensino/práticas pedagógicas, que abarcava os diferentes componentes curriculares no contexto da educação escolar, foram listados para a procura de trabalhos.

${ }^{7} \mathrm{~A}$ área de avaliação Ensino possui uma diversidade de programas em função da sua natureza multidisciplinar. Como critério de seleção para esta pesquisa, os programas que apresentavam o Ensino de Ciências e Matemática como área básica, automaticamente foram consultados. Enquanto aqueles que estavam vinculados à área de Ensino (área básica), os seus sites foram examinados para verificar se as linhas de investigação contemplavam o desenvolvimento de pesquisas sobre o ensino de ciências na Educação Básica.
} 
A primeira diz respeito às pesquisas que trouxeram como problemas de investigação situações de ensino (currículos, programas, recursos didáticos, formação de professores, conteúdo e método, características do professor), envolvendo, portanto, as atividades dos professores (leigos formados). A segunda tipificação reúne investigações sobre os alunos (leigos) nos aspectos de seus pensamentos e cognição (SLONGO, 2004).

A totalidade da produção científica (84) identificada por este estudo está distribuída entre 2004 e 2015, período em que foi observado picos de publicação nos anos de 2009 e 2013 (PARANHOS; CARNEIRO, 2019b). Os dados mostram que o ensino de biologia na relação com a modalidade EJA não se constituiu, de imediato, objeto de análise no CPEC e revelam a existência de três períodos que caracterizam a produção científica analisada: i) Período A (1996 - 2003): não houve publicação de trabalhos sobre o ensino de biologia na EJA; ii) Período B (2004 - 2009): produção científica sobre a atividade do CExo (leigos e leigos formados); iii) Período C (2010 - 2015): mantém a tendência do período "B" mas com a publicação das primeiras teses e relatos de experiencia.

A Tabela 1 indica que 70,3\% da produção científica esteve relacionada às atividades do CExo dos leigos formados (professores), sendo o período "C" o que apresenta maior quantidade dessa produção. Sobre as pesquisas que focaram as atividades do CExo dos leigos (alunos), a centralidade da produção também está no período "C", com um quantitativo de $16,6 \%$ do total de publicações. Foi identificado dois trabalhos (A12 e A17) sobre a atividade do CEso (CPEC), em que as produções científicas sobre ensino de biologia na EJA foram tomadas para análise. Esses trabalhos foram escritos no contexto da elaboração das dissertações DA17 e DF11, respectivamente.

Tabela 1 - Tipificação das pesquisas considerando o CExo (leigos formados e leigos) e CEso (CPEC).

\begin{tabular}{|c|c|c|c|}
\hline \multirow[b]{2}{*}{ Tipos } & \multicolumn{2}{|c|}{ Períodos } & \multirow[b]{2}{*}{$\begin{array}{c}\text { Total } \\
(\%)\end{array}$} \\
\hline & $\begin{array}{c}\text { B } \\
(2004-2009)\end{array}$ & $\begin{array}{c}C \\
(2010-2015)\end{array}$ & \\
\hline $\begin{array}{l}\text { Pesquisas relativas às atividades do CExo dos leigos formados } \\
\text { (professores formados) }\end{array}$ & 26 & 33 & $\begin{array}{c}59 \\
(70,3) \\
\end{array}$ \\
\hline Pesquisas relativas às atividades do CExo dos leigos (alunos) & 5 & 9 & $\begin{array}{c}14 \\
(16,6)\end{array}$ \\
\hline Pesquisas relativas às atividades de pesquisa do CEso (CPEC) & - & 2 & $\begin{array}{c}2 \\
(2,4) \\
\end{array}$ \\
\hline Outros & 1 & 8 & $\begin{array}{c}9 \\
(10,7) \\
\end{array}$ \\
\hline Total & 32 & 52 & $\begin{array}{c}84 \\
(100)\end{array}$ \\
\hline
\end{tabular}

Fonte: Paranhos (2017). 


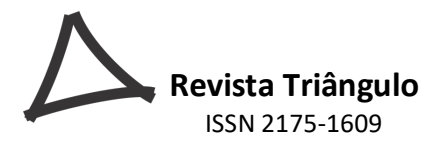

Os dados da Tabela 1 sinalizam as tendências de pesquisa que têm como problemas de investigação as atividades do CExo (leigos formados) e CExo (leigos), em que a primeira apresentou maior quantidade de estudos. Slongo (2004) em sua pesquisa analisou a produção científica brasileira (dissertações e teses) sobre o ensino de biologia $(1972-2000)$ e identificou semelhante tendência.

Compreende-se que este artigo caracteriza um matiz de pensamento (coleur du pensée) do Coletivo de Pesquisadores Educação em Ciências (CPEC), pois a totalidade da produção científica sobre o ensino de biologia não se reduz ao recorte analítico empreendido por este trabalho. Dito isto, este artigo mostra que o aspecto estilístico vinculado aos problemas de pesquisa sobre o ensino de biologia na EJA delineou tendências semelhantes à investigação já consolidada, quando considerada a totalidade da produção científica sobre o ensino de biologia no Brasil. Tal afirmação se sustenta, quando tomamos os trabalhos de Megid-Neto (1999) Slongo (2004) e Teixeira (2008) para fazer um paralelo entre os resultados da nossa investigação com os resultados desses estudos.

A identificação dos problemas de pesquisa sinalizou os temas que a produção científica contemplou. Adota-se neste artigo a compreensão de que o tema/foco temático é identificado a posteriori da execução da pesquisa, pois como destaca Gamboa (2007), uma investigação se dá em torno da busca de respostas a problemas de aspectos da realidade e não de temas da realidade. O tema seria uma categoria que agrupa as pesquisas que problematizaram determinados aspectos da realidade e, enquanto tal, é um relevante instrumento simbólico a ser considerado na análise da produção do conhecimento científico, na medida em que lança luz para compreensão dos elementos problematizadores da pesquisa que foi desenvolvida. Portanto, o tema é engendrado a partir dos problemas de pesquisa e configura um aspecto do estilo de pensamento de um determinado campo de investigação.

Este trabalho emprega a ideia de Foco Temático proposta por Megid-Neto (1999) para categorizar as pesquisas. Teixeira (2008, p. 60), em seu estudo, empregou essa ideia, pois avalia que é "[...] um dos mais importantes indicadores para a análise de tendências da produção acadêmica, já que permite a reflexão sobre os temas e problemáticas que tem recebido maior atenção por parte dos pesquisadores [...]”. Slongo (2004) entende que o Foco Temático é um elemento constitutivo de um estilo de pensamento, pois a partir dele compreende-se o modo pelo qual se propôs problemas de investigação. 
As Tabelas 2 e 3 apresentam os problemas presentes na produção científica (artigos, dissertações e teses) sobre ensino de biologia na EJA e destacam os Focos Temáticos dessa produção. A definição dos focos identificados por este artigo baseou-se nos trabalhos de MegidNeto (1999), Machado (2002), Souza (2002) e Teixeira (2012) em que se manteve as descrições originais e/ou foram feitas adaptações, obtendo as seguintes caracterizações:

Currículo - estudos dos princípios, parâmetros, diretrizes e fundamentos teórico-metodológicos para o ensino de ciências e biologia, contemplando os diversos elementos convencionalmente atribuídos ao desenho curricular: objetivos educacionais, conteúdos, estratégias, avaliação etc. Discussão do papel da escola, das relações entre a ciência e sociedade, e outros aspectos do sistema educacional. Avaliação de propostas curriculares de EJA, de reformas curriculares, projetos pedagógicos ou projetos educacionais para a modalidade. Proposição e desenvolvimento de programas ou propostas alternativas de ensino de ciências para uma série, disciplina, semestre letivo ou ciclo escolar completo (MEGIDNETO, 1999, p. 134; TEIXEIRA, 2012, p. 12).

Educando(a) - pesquisas que têm como foco compreender as características sociais, políticas, econômicas e culturais dos educandos da EJA; as visões que estes possuem da escola e do seu processo de aprendizagem, incluindo aí as expectativas e decepções em relação à escolarização. Estudos que buscam compreender como os educandos se apropriam dos conceitos científicos; o estabelecimento da relação entre conceitos espontâneos e científicos, com vistas à elaborações conceituais mais complexas por parte dos educandos (Adaptado de MEGID-NETO, 1999, p. 135; TEIXEIRA, 2012, p. 13; MACHADO, 2002, p. 47).

Ensino - produções científicas que contemplam o ensino de ciências na educação escolar (EJA) sob a ótica dos aspectos metodológicos (aplicação de métodos e técnicas de ensino - sequências didáticas, unidades didáticas, aulas práticas, aulas de campo, etc.); abordagens diferenciadas no ensino de ciências (por temas, gênero, sexualidade, bioética, história e filosofia da ciência); emprego de diferentes recursos didáticos no ensino (livro didático, livro paradidático, textos de divulgação científica, filmes, jogos, etc.); elaboração de recursos didáticos para o ensino; emprego de diferentes modalidades didáticas; criação e implementação de estratégias de ensino diferenciadas (Adaptado de MEGID-NETO 1999, p. 134-135; TEIXEIRA, 2012, p. 12).

Professor(a) - estudos que caracterizam e analisaram as condições profissionais dos professores da área de ciências/biologia, bem como, os aspectos social, político e econômico. Estudos que focam a análise dos saberes docentes, concepções sobre teoria-prática, concepções de ciências, concepções sobre a natureza da ciência. Análise da prática pedagógica do(a) professor(a) ao ensinar ciências/biologia. Pesquisas que problematizam a formação inicial e continuada de professores de ciências/biologia (Adaptado de MEGID-NETO 1999, p. 134-135; TEIXIERA, 2012, p. 12).

Produção científica - estudos que priorizaram a análise da produção científica (artigos, dissertações e teses) sobre o ensino de ciências/biologia na educação de jovens e adultos em que são destacados temas, problemas, objetivos, aspectos metodológicos e contribuições para a educação em ciências.

Políticas/Programas - pesquisas que abordaram programas, diretrizes, ações e políticas públicas de escolarização de jovens e adultos em diferentes níveis do governo, voltados para o público em geral e relacionado com um conjunto de problemas da coletividade, desde que explicitadas suas repercussões ou ligações com a educação científica/educação de jovens e adultos e o ensino de e ciências nessa modalidade (Adaptado de MEGID-NETO, 1999, p. 135; TEIXEIRA, 2012, p. 14; SOUZA, 2002, p. $85)$.

Com base na produção científica analisada, apresentou-se problemas que permitiram delimitar os seguintes focos temáticos: i) Ensino; ii) Educando(a); iii) Professor(a); iv) Currículo; v) Produção Científica; vi) Políticas/Programas e; vii) Outros (Tabela 2 e 3).

Entende-se que a produção científica abarca a publicação de artigos em periódicos, dissertações e teses. Contudo, a atividade que origina essa produção pode apresentar diferenças, sobretudo quando considerada a publicação de artigos, pois estes podem ser frutos da atividade de pesquisa ou relatos sobre uma prática de ensino desenvolvida em espaços de ensinoaprendizagem. Com isso, justifica-se apresentar separadamente os dados advindos dos artigos 
(Tabela 2), valendo-se das categorias propostas por Araújo e Carneiro (2014) - Relato de Pesquisa (RP) e Relato de Experiência (RE).

Tabela 2 - Foco temático dos artigos que abordaram o ensino de biologia na EJA.

\begin{tabular}{|c|c|c|c|c|c|c|}
\hline \multirow{3}{*}{ Foco Temático } & \multirow{3}{*}{ Problema* } & \multicolumn{4}{|c|}{ 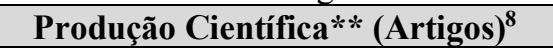 } & \multirow{3}{*}{$\begin{array}{c}\text { Total } \\
(\%)\end{array}$} \\
\hline & & \multicolumn{2}{|c|}{ (B) } & \multicolumn{2}{|c|}{ (C) } & \\
\hline & & $\mathbf{R P}$ & $\mathbf{R E}$ & $\mathbf{R P}$ & RE & \\
\hline \multirow{5}{*}{ Ensino } & $\begin{array}{c}\text { Abordagem do tema - Gênero e } \\
\text { Sexualidade }\end{array}$ & $\begin{array}{l}\text { A14, } \\
\text { A15 }\end{array}$ & - & - & - & \multirow{5}{*}{$\begin{array}{c}15 \\
(53,6)\end{array}$} \\
\hline & Abordagem do tema - Bioética ${ }^{54}$ & A4 & - & - & - & \\
\hline & $\begin{array}{l}\text { Aspectos Metodológicos do } \\
\text { Ensino }\end{array}$ & A22 & - & $\begin{array}{c}\text { A6, A7, } \\
\text { A9, A18, } \\
\text { A21, } \\
\text { A26 }\end{array}$ & A19 & \\
\hline & Recurso Didático & A28 & - & - & $\mathrm{A} 10, \mathrm{~A} 11$ & \\
\hline & Práticas de Leitura & - & - & A24 & - & \\
\hline \multirow{2}{*}{ Currículo } & $\begin{array}{l}\text { Enfoque Ciência, Tecnologia e } \\
\text { Sociedade }\end{array}$ & A23 & - & - & - & \multirow{2}{*}{$\begin{array}{c}\mathbf{0 3} \\
(10,7)\end{array}$} \\
\hline & Propostas Curriculares Oficiais & $\begin{array}{l}\text { A27, } \\
\text { A8 }\end{array}$ & - & - & - & \\
\hline \multirow{3}{*}{ Professor(a) } & Formação Inicial & A13 & - & - & - & \multirow{3}{*}{$\begin{array}{c}\mathbf{0 3} \\
(10,7)\end{array}$} \\
\hline & Concepções & A20 & - & - & - & \\
\hline & Prática Pedagógica & - & - & - & $\mathrm{A} 25$ & \\
\hline \multirow[b]{2}{*}{ Educando(a) } & Escolarização/Ed. Científica & A16 & - & - & - & \multirow[b]{2}{*}{$\begin{array}{c}\mathbf{0 5} \\
(17,8)\end{array}$} \\
\hline & Concepções/Conhecimentos & - & - & $\begin{array}{l}\text { A1, A2, } \\
\text { A3, A5 }\end{array}$ & - & \\
\hline Produção Científica & $\begin{array}{l}\text { Estado do Conhecimento - } \\
\text { Ensino de Ciências na EJA }\end{array}$ & - & - & $\begin{array}{l}\text { A12, } \\
\text { A17 }\end{array}$ & - & $\begin{array}{c}\mathbf{0 2} \\
(7,2) \\
\end{array}$ \\
\hline & TOTAL & $\begin{array}{c}11 \\
(39,3)\end{array}$ & $\begin{array}{c}\mathbf{0} \\
(0)\end{array}$ & $\begin{array}{c}13 \\
(46,4)\end{array}$ & $\begin{array}{c}\mathbf{0 4} \\
(14,3)\end{array}$ & $\begin{array}{c}28 \\
(100)\end{array}$ \\
\hline
\end{tabular}

Fonte: Paranhos (2017). * Para os Relatos de Experiência, entende-se que os problemas emergem da prática de ensinar ciências na EJA. ** A produção científica do tipo artigo foi identificada com o emprego da letra "A" seguida de numeração arábica (A1...A28). A relação completa dos artigos analisados pode ser encontrada em Paranhos (2017).

Tabela 3 - Foco temático e problemas de pesquisas (dissertações e teses).

\begin{tabular}{|c|c|c|c|c|}
\hline \multirow[t]{2}{*}{ Foco Temático } & \multirow[t]{2}{*}{ Problema } & \multicolumn{2}{|c|}{$\begin{array}{l}\text { Produção Científica* } \\
\text { (Dissertação e Tese) }\end{array}$} & \multirow{2}{*}{$\begin{array}{c}\text { Total } \\
(\%)\end{array}$} \\
\hline & & (B) & (C) & \\
\hline $\begin{array}{l}\text { Politicas / } \\
\text { Programas }\end{array}$ & PROJOVEM & DA4 & - & $\begin{array}{c}\mathbf{0 1} \\
(1,8)\end{array}$ \\
\hline \multirow{4}{*}{ Ensino } & $\begin{array}{l}\text { Abordagem do tema - Gênero e } \\
\text { Sexualidade }\end{array}$ & DF16, & DA18, DA54 & \multirow{4}{*}{$\begin{array}{c}\mathbf{2 6} \\
(46,4)\end{array}$} \\
\hline & Abordagem do tema - Bioética & DA50 & - & \\
\hline & Aspectos Metodológicos do Ensino & $\begin{array}{c}\text { DF24, DA51, } \\
\text { DA55 }\end{array}$ & $\begin{array}{l}\text { DF1, DF2, DF7, DF9, } \\
\text { DA10, DF11, DF12, } \\
\text { DF22, DF23, DF25, } \\
\text { DA42, DA45, DF52, }\end{array}$ & \\
\hline & $\begin{array}{l}\text { História e Filosofia da Ciência no } \\
\text { Ensino }\end{array}$ & - & DA13 & \\
\hline
\end{tabular}

\footnotetext{
${ }^{8}$ Embora o Período B abarque o intervalo entre os anos de 2004 e 2009, cabe destacar que os primeiros artigos publicados sobre ensino de biologia na EJA foram em 2005.

${ }^{9} \mathrm{O}$ critério empregado para a classificação das pesquisas nos subgrupos do Ensino está ligado à ideia dos temas transversais (Sexualidade, Ética, Saúde, Meio Ambiente, Pluralidade Cultural, Trabalho e Consumo).
} 


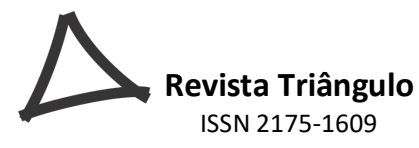

\begin{tabular}{|c|c|c|c|c|}
\hline \multirow[t]{6}{*}{ Foco Temático } & \multirow[t]{2}{*}{ Problema } & \multicolumn{2}{|c|}{$\begin{array}{l}\text { Produção Científica* } \\
\text { (Dissertação e Tese) }\end{array}$} & \multirow{2}{*}{$\begin{array}{c}\text { Total } \\
(\%)\end{array}$} \\
\hline & & (B) & (C) & \\
\hline & Letramento Científico & DA30 & - & \\
\hline & Interações Argumentativas & - & DA37 & \\
\hline & Recurso Didático & DA35, DF38 & - & \\
\hline & Práticas de Leitura & - & DA36 & \\
\hline \multirow{4}{*}{ Currículo } & Currículo & $\begin{array}{l}\text { DA29, DA33, } \\
\text { DA56 }\end{array}$ & T26, T34, DA46, & \multirow{4}{*}{$\begin{array}{c}09 \\
(16,1)\end{array}$} \\
\hline & $\begin{array}{c}\text { Enfoque Ciência, Tecnologia e } \\
\text { Sociedade }\end{array}$ & DA53 & - & \\
\hline & Propostas Curriculares Oficiais & - & DA17 & \\
\hline & $\begin{array}{c}\text { Proposta Político - Pedagógica de } \\
\text { EJA }\end{array}$ & - & DA14 & \\
\hline \multirow{4}{*}{ Professor(a) } & Formação Inicial & - & DA15, DA39 & \multirow{4}{*}{$\begin{array}{c}\mathbf{0 9} \\
(16,1)\end{array}$} \\
\hline & Concepções & DA20 & & \\
\hline & Práticas Pedagógicas & $\begin{array}{l}\text { DA21, DA27, } \\
\text { DA43, }\end{array}$ & DA40, DA47 & \\
\hline & Saberes & - & DA44 & \\
\hline \multirow{5}{*}{ Educando(a) } & Apropriação de conceitos científicos & DA19, DA28, & DF5, DA8, DA41 & \multirow{5}{*}{$\begin{array}{c}11 \\
(19,6)\end{array}$} \\
\hline & Concepções/Conhecimentos & DA49 & DF3, DF6, DA48 & \\
\hline & Experiência de aprender ciências & DA32 & - & \\
\hline & Escolarização/Ed. Científica & - & - & \\
\hline & Temas científicos de interesse & - & DF31 & \\
\hline & TOTAL & $\begin{array}{c}\mathbf{2 1} \\
(37,5)\end{array}$ & $\begin{array}{c}\mathbf{3 5} \\
(62,5)\end{array}$ & $\begin{array}{c}\mathbf{5 6} \\
(100)\end{array}$ \\
\hline
\end{tabular}

Fonte: Paranhos (2017). *A produção científica do tipo dissertação foi identificada com o emprego da letra "D" seguida letras "F" - mestrado profissional - e A - mestrado acadêmico - e numeração arábica (DF1...DA8...DA56). A produção científica do tipo tese foi identificada com o emprego da letra " $T$ " seguida de numeração arábica (T26 T34). A relação completa de dissertações e teses analisadas pode ser encontrada em Paranhos (2017).

A Tabela 2 explicita uma questão a ser discutida pelo Coletivo de Pesquisadores Educação em Ciências, pois nela fica posto que a produção científica também abarca os artigos do tipo Relato de Experiência que, não necessariamente, surge de uma problematização da realidade, mas sim de enfrentamentos que parecem ser resolvidos com a proposição de metodologias para ensinar biologia na EJA. Alinham-se a essa acepção os trabalhos A10, A11e A19. Os objetivos dos relatos de experiência indicam que a proposição metodológica se deve a fatores externos à Educação de Jovens e Adultos, conforme ilustram os fragmentos de texto abaixo:

Deste modo, o presente artigo apresentará os resultados obtidos a partir da produção de um jogo didático, intitulado 'No mundo das plantas', desenvolvido com conteúdos de botânica. $\mathrm{O}$ mesmo teve como finalidade refletir sobre essa importante ferramenta de ensino, através da sua aplicabilidade em uma turma de EJA (Educação de Jovens e Adultos) (A10, p. 555).

Este trabalho tem-se como objetivo utilizar a experimentação prática atrelada a uma questão problematizadora como ferramenta facilitadora do aprendizado sobre os principais conceitos relacionados a substâncias e misturas com alunos do Ensino de Jovens e Adultos (EJA) do fundamental II (A11, p. 1846). 
Tendo em vista todos os problemas com relação ao uso do cigarro, este trabalho descreve uma ação interventiva pontual, realizada na 'Semana da Educação para a Vida' (conforme o calendário escolar da Secretaria de Educação do Distrito Federal - SEDF -, realizado em maio - mesmo mês de celebração do 'Dia Mundial Sem Tabaco'), tendo como tema 'A interferência da indústria tabagista', junto aos alunos de uma escola da modalidade de Educação de Jovens e Adultos (EJA), sobre os perigos do fumo (A19, p. 5).

Em que medida o "Dia mundial Sem Tabaco", o jogo didático e a experimentação consideraram a prática social da EJA proporcionando aos educandos a apropriação dos conceitos científicos? As proposições metodológicas estabelecidas a priori e descoladas da prática social da EJA pouco contribuem com a objetivação da realidade e, portanto, não geram a construção de instrumentos simbólicos (conceitos) para complexificar o ensino de biologia tendo a EJA como ponto de partida e de chegada. Os Relatos de Experiência já partem de pressupostos metodológicos para a superação de desafios que se colocam na aparência do processo de ensino-aprendizagem, não considerando aspectos como: i) a aprendizagem do conceito científico pelo jovem e o adulto; ii) a discussão que considera as relações que permitam compreender a maneira pela qual os aspectos metodológicos possibilitam a apropriação do conceito científico pelo educando da EJA. Longe dessas referências, as produções do tipo Relato de Experiência, apresentam considerações que parecem estar vinculadas apenas à dimensão metodológica empregada na intervenção, e não ao processo de apropriação dos conceitos científicos, como ilustram os fragmentos a seguir:

\footnotetext{
No final, enquanto respondiam o questionário (pós-teste), perceberam que adquiriram um conhecimento mais abrangente sobre o tema. Alguns ficaram surpresos em aprender, 'sem ter que fazer trabalho de escola', resumindo assim alguns comentários de alguns alunos após a realização da atividade (A10, p. 562).

A apresentação de atividades com uma abordagem mais prática pode oferecer um maior significado tanto para o aluno quanto para o docente, especialmente para turmas de EJA que carecem de motivação, assiduidade participação e concentração nas atividades (A11, p. 1852-1853).

Especificamente sobre o filme, a maioria disse ter gostado, uma vez que ele é ao mesmo tempo engraçado e sério, sendo considerado por G. (26 anos), como um documentário (Pô, parece até que é de verdade, que aconteceu mesmo) (A19, p. 7).
}

As experiências de atividades de ensino desenvolvidas na escola e relatadas no formato de artigos apresentam o potencial de trazer contribuições para a produção científica que se estabelece no CPEC, desde que atentem à aprendizagem dos conceitos científicos pelos adultos e sejam mais resolutas quanto a perspectiva teórica empregada para analisar o processo de ensino-aprendizagem.

A avaliação do aspecto metodológico empregado numa prática de ensino de biologia na EJA deve ter em conta, como uma das determinações, a apropriação do conceito científico pelos 
educandos da modalidade. Sem a clareza desta determinação, a avaliação das metodologias perde sentido e não se justifica quando se entende que o objetivo da educação escolar e o papel do professor no processo de ensino-aprendizagem se dão em função da apropriação dos conhecimentos científicos. O aspecto metodológico é um desdobramento flexível quanto ao seu tipo e deve estar em função do conceito científico a ser ensinado e do público a que se ensina.

Gamboa (2007) faz um alerta sobre a inversão que se coloca quando os objetivos de pesquisa se confundem com os objetivos de uma proposta de intervenção, pois esta pode atribuir à pesquisa científica um poder enganador de transformação da realidade. $\mathrm{O}$ autor ainda destaca que a pesquisa é um processo exaustivo e rigoroso pela busca da compreensão dos problemas de pesquisa estabelecidos pelo pesquisador e sinaliza que é pelo diagnóstico exaustivo da problemática que se instalam as possibilidades de transformação da realidade.

As Tabelas 2 e 3 mostram o aumento na produção científica sobre o ensino de biologia na EJA (artigo, dissertação e tese). O paralelo estabelecido entre as tabelas, ainda constata: i) diferentes tipos de produção problematizaram a realidade de maneira a se desdobrar nos mesmos focos temáticos, exceto a produção científica do tipo artigo, pois esta não apresentou o foco Políticas/Programas; ii) a centralidade quantitativa para foco temático Ensino em seus aspectos metodológicos, sendo que o período "C" apresenta uma proeminente produção que considera esse aspecto; iii) o período "C" é diferente do período "B", pois nele foram publicados artigos no formato Relato de Experiência, bem como, as primeiras teses de doutorado, tipos de produção não observados em períodos anteriores.

Considerados os artigos (Relato de Pesquisa), dissertações e teses distribuídos nos períodos "B" e "C" (Tabela 2 e 3), nota-se características distintas para a produção científica desses períodos, nos seguintes aspectos: i) quantidade; ii) foco temático/problemas priorizados; iii) foco temático/problemas na relação com a natureza dos programas de pós-graduação (mestrado acadêmico e profissional).

O período "B" (2004 - 2009) contém 32 (40\%) produções distribuídas em 11 artigos e 21 dissertações. Desse montante, 26 problematizaram as atividades do CExo dos leigos formados em que se destaca o foco temático ensino (13), currículo (07) e professor (06). O restante deteve-se ao CExo dos leigos com o foco temático nos(as) educandos(as) (05) da EJA. Houve uma produção que problematizou as políticas/programas, entendida aqui como aspectos externos ao CExo (leigos formados) e ao CExo (leigos). 


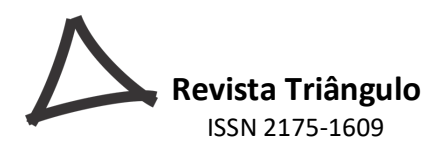

O período "C" (2010 - 2015) responde pela publicação de 48 (60\%) produções (13 artigos, 33 dissertações e 02 teses). Neste período as investigações problematizaram as atividades do CExo dos leigos formados, em que os focos temáticos estiveram ligados ao ensino (25), currículo (05) e professor (05). O(a) educando(a), CExo dos leigos, foi foco temático de 11 produções. O período em questão é caracterizado ainda pela produção científica (02) que problematizou a atividade o CEso (especialistas/pesquisadores).

O paralelo estabelecido entre os períodos da produção (Tabela 2 e 3), permite afirmar que o período "C" manteve a tendência de investigação sinalizada pelo período "B", mas notase uma intensificação nos seus aspectos quantitativos, principalmente quando se observa a produção da pesquisa em programas de pós-graduação (dissertações e teses). Um traço distintivo do período "C" em relação ao "B" é a publicação de artigos no formato de Relatos de Experiência; das primeiras teses de doutorado sobre o ensino de biologia na EJA e de artigos que explicitam as características da produção científica do CEso.

Sobre o foco temático/problema das pesquisas que abarcam as atividades do CExo dos leigos formados (professores), a centralidade da produção científica dos períodos "B" e "C" deteve-se no Ensino (13 e 25) em seus aspectos metodológicos (04 e 19). Para os focos temáticos currículo e professor não foi identificada uma diferença acentuada quanto a produção ligada a esses temas e nos dois períodos. Quanto ao foco temático/problema das investigações sobre as atividades do CExo leigos (educandos), houve aumento em "C" de produções (11) que problematizaram os conhecimentos e concepções dos alunos da EJA.

Considerada a origem (programas de pós-graduação) das pesquisas (dissertações e teses) distribuídas entre os períodos “B” e "C", há diferença na publicação e está vinculada à natureza do programa de pós-graduação (acadêmico - MA - e profissional - MF -). O primeiro aspecto dessa diferença é quantitativo, pois no período "B" foram encontradas 18 pesquisas de MA, o que demonstra um predomínio em relação ao MF (03). No intervalo de tempo subsequente (Período C - Tabela 3) sobressai a quantidade de pesquisa oriunda de MF (14) em relação ao aumento das que foram produzidas por MA (21).

O aumento quantitativo é explicado pelos marcos institucionais regulamentadores envolvidos na expansão da pós-graduação (modalidade profissional). Entende-se que a dimensão quantitativa não constitui, por si só, um aspecto determinante para o desenvolvimento e/ou mudanças observadas no Estilo de Pensamento Educação em Ciências (EPEC), pois há de 
se considerar o projeto formativo disposto nos marcos regulamentadores brasileiros (Portarias MEC n $n^{\circ} 17 / 2009$ e no 389/2017) para a modalidade profissional da pós-graduação.

O Art. 4 da Portaria MEC n 17/2009 explicita que um dos objetivos dos MF é "capacitar profissionais qualificados para o exercício da prática profissional avançada e transformadora de procedimentos, visando atender demandas sociais, organizacionais ou profissionais e do mercado de trabalho" (BRASIL, 2009, p. 21). Nesse mesmo documento (Parágrafo Único do Art. 5) a formação oferecida pelo MF tem como princípios os seguintes aspectos: a) Aplicabilidade técnica; b) Utilização aplicada dos conhecimentos; c) Exercício da inovação; d) Valorização da experiência profissional.

A Portaria MEC n ${ }^{\mathrm{o}} 389 / 2017$ revoga a Portaria Normativa MEC n 17/2009, amplia o oferecimento da pós-graduação profissional ao instituir o doutorado nessa modalidade e apresenta, como necessário, "o estreitamento das relações entre as universidades e o setor produtivo" (BRASIL, 2017, p.61). Em linhas gerais, os objetivos da normativa em destaque abarcam: a) uma prática profissional em que haja transformação de procedimentos; b) atendimento a demandas dos arranjos produtivos; c) solução de problemas de modo inovador com vistas à melhoria da eficácia e eficiência de organizações públicas e privadas; d) agregar e aumentar produtividade.

Em relação à Portaria 17/2009, o documento em vigência é mais sucinto, porém mais resoluto com a lógica do mercado. Ele explicita a relação que se estabelece entre a educação institucionalizada e o modo produtivo, já que o mercado e os arranjos produtivos constituem o ponto de partida e de chegada das produções acadêmicas desses mestrados. O projeto formativo posto se volta à formação de produtos (recursos humanos) chancelados pelos títulos de mestre e doutor a serem consumidos pelo mercado de trabalho de forma competitiva, pois o mestrado e o doutorado conferem a alta qualificação. Soma-se a isso a possibilidade de tornar a atividade científica mais produtiva em concordância com a lógica do mercado.

A análise da pesquisa sobre o ensino de biologia na EJA desvela uma tendência investigativa que coloca em relevo o foco temático ensino em que são problematizados os aspectos metodológicos deste. Essa tendência se acentuou no período 2010 - 2015 (C) e os dados indicam que os mestrados profissionais com seus projetos formativos foram determinantes para se estabelecer a centralidade dada ao foco em questão (Tabela 3 e Quadro 1). O projeto formativo da pós-graduação na modalidade profissional delineado pelos documentos supramencionados ilustra o que Fleck (2008) avulta sobre os fatores externos 
envolvidos na produção do conhecimento científico, o que permite inferir que as orientações contidas nesses documentos incidiram sobre os problemas de pesquisa das dissertações de MF. $\mathrm{O} \S 3^{\circ}$ do Art. $7^{\circ}$ da Portaria 17/2009 explicita os diferentes formatos para a elaboração do trabalho de conclusão de curso do MF que, para o contexto de um mestrado em ensino de ciências, abarcaria: dissertação, desenvolvimento de aplicativos, materiais didáticos e instrucionais e de produtos, processos e técnicas, protocolo experimental ou de aplicação em serviços, protótipos para desenvolvimento ou produção de instrumentos, equipamentos e kits (BRASIL, 2009, p. 21). O Quadro 1 expõe exemplos de produtos das pesquisas brasileiras sobre ensino de biologia na EJA.

Quadro 2 - Produção científica de MF e os produtos para o ensino de biologia na EJA.

\begin{tabular}{|c|c|c|c|}
\hline Produção & Problema & Produto & FT* \\
\hline DF1 & \multirow{11}{*}{ 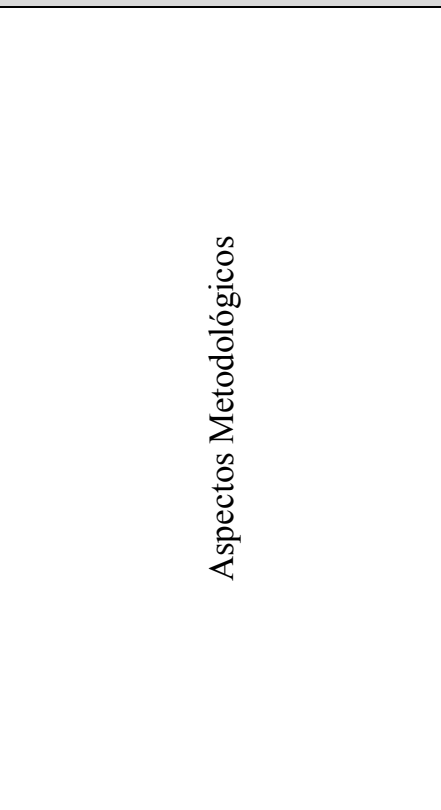 } & $\begin{array}{l}\text { Proposta de Ação Profissional (Roteiro para } \\
\text { Discussão de Filmes) }\end{array}$ & \multirow{13}{*}{$\begin{array}{l}\stackrel{ }{\Xi} \\
\text { 式 }\end{array}$} \\
\hline DF2 & & $\begin{array}{l}\text { Proposta de Intervenção nas aulas de ciências } \\
\text { na EJA }\end{array}$ & \\
\hline DF7 & & Não disponibilizado & \\
\hline DF9 & & $\begin{array}{l}\text { Proposta de Ação Profissional (Ed. Saúde e } \\
\text { Divulgação Científica) }\end{array}$ & \\
\hline DF11 & & $\begin{array}{l}\text { Proposta de Ação Profissional (Sequência de } \\
\text { Ensino) }\end{array}$ & \\
\hline DF12 & & $\begin{array}{l}\text { Produto Educacional (Apresentação de Slides } \\
\text { em Power Point) }\end{array}$ & \\
\hline DF22 & & Produto Final (Textos de Apoio ao Professor) & \\
\hline DF23 & & $\begin{array}{l}\text { Produto Educacional (Livreto - Atividades de } \\
\text { Caráter Investigativo) }\end{array}$ & \\
\hline DF24 & & Não disponibilizado & \\
\hline DF25 & & $\begin{array}{l}\text { Produto Final (Material Didático } \\
\text { Interdisciplinar - Plantas Medicinais) }\end{array}$ & \\
\hline DF52 & & $\begin{array}{l}\text { Produto Final (Sequência Didática - Vozes na } \\
\text { EJA) }\end{array}$ & \\
\hline DF16 & Gênero e Sexualidade & $\begin{array}{l}\text { Proposta de Ação Profissional (Proposição } \\
\text { Didática) }\end{array}$ & \\
\hline DF38 & Recurso Didático & $\begin{array}{l}\text { Produto Final (Guia Didático com sinopses de } \\
\text { filmes - Cine Aula) }\end{array}$ & \\
\hline DF3 & \multirow{2}{*}{$\begin{array}{l}\text { Concepções/ } \\
\text { Conhecimentos }\end{array}$} & Proposta de Intervenção (Temas Geradores) & \multirow{4}{*}{ 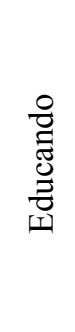 } \\
\hline DF6 & & $\begin{array}{l}\text { Produto Educacional (Guia orientado para o } \\
\text { professor de ciências) }\end{array}$ & \\
\hline DF5 & $\begin{array}{l}\text { Apropriação de conceitos } \\
\text { científicos }\end{array}$ & $\begin{array}{l}\text { Sequência de Ensino de Conceitos Ecológicos } \\
\text { Sistêmicos na Educação de Jovens e Adultos } \\
\text { (EJA) }\end{array}$ & \\
\hline DF31 & Temas científicos de interesse & $\begin{array}{l}\text { Produto Educacional (Projeto Piloto de Rádio } \\
\text { Escolar para EJA) }\end{array}$ & \\
\hline
\end{tabular}

Fonte: Paranhos (2017). * FT - Foco Temático.

O desenvolvimento de materiais instrucionais e didáticos se materializam como produtos a serem consumidos por outros professores, o que pode levar à compreensão ingênua que isso seria a atividade fim do desenvolvimento de uma pesquisa. A pesquisa é aqui 
compreendida como o meio pelo qual o homem objetiva a realidade (educativa) e desenvolve conhecimento. Esse conhecimento ao ser apropriado por outro professor possibilita a este objetivar a sua prática educacional por meio do conhecimento apropriado anteriormente, num processo de complexificação cada vez mais abrangente em relação ao seu fazer docente.

Entende-se que se a ênfase é dada aos produtos, isso pode corroborar uma perspectiva técnica de ensino, pois focaliza os aspectos da eficiência do ensino de ciências (OSTERMANN; REZENDE, 2009). Para essas autoras, superar essa visão, seria necessário que esses produtos contemplassem uma reflexão mais ampla sobre os enfrentamentos e os problemas educacionais colocados aos docentes. Ademais, o objetivo do mestrado é formar pesquisadores que, por meio do rigor teórico metodológico, produzem conhecimento científico. Tal objetivo, não pode se confundir com uma etapa de "escolarização de alto nível, nem pode ser confundido com formação contínua de profissionais da educação [...] (LARROCA; ROSSO; SOUZA, 2005, p. 121). Para esses autores, o mestrado pode abarcar os aspectos de uma formação continuada sem, contudo, configurar a razão da existência de um mestrado e/ou doutorado.

Numa relação mais específica com a formação de professores, as Portarias 17/2009 e $389 / 2017$, patenteiam a epistemologia da prática, na medida em que as produções devem voltarse para a solução de problemas específicos. Trata-se de documentos perversos com a formação de professores, posto que corrobora com os processos que atribuem ao docente a responsabilidade pelos insucessos da escola. O docente com uma formação altamente qualificada, como marcam os documentos, possivelmente não resolverá os problemas específicos da educação escolar e sua prática, pois a escola está inserida numa realidade concreta, sendo, portanto, a síntese de múltiplas determinações.

Embora este artigo evidencie a participação de MF na produção de pesquisas que problematizaram os aspectos metodológicos do ensino de biologia na EJA, isso não se deu de forma exclusiva para o estabelecimento dessa tendência investigativa no período " $\mathrm{C}$ ", pois houve pesquisas (DA10, DA42, DA45, DA51 e DA55) desenvolvidas em MA que também problematizaram os aspectos metodológicos do ensino.

\section{CONSIDERAÇÕES FINAIS}

Tendo em vista a sistematização e análise dos dados, este artigo explicita uma tendência, em termos quantitativos $(70,3 \%)$ da pesquisa sobre o ensino de biologia na EJA está relacionada à produção de conhecimento a partir de problematizações vinculadas às atividades do CExo 
dos leigos formados (professores(as) da educação básica). A respeito dessas atividades, o foco temático Ensino presente em pesquisas (dissertações e teses) possui centralidade quantitativa (46,4\%) em relação aos demais - Políticas/Programas (1,8\%), Currículo (16,1\%), Professor $(16,1 \%)$ e Educando $(19,6 \%)-$.

As análises indicaram que a centralidade em torno do foco temático Ensino e seus aspectos metodológicos se acentuou no período 2010 - 2015, e indicam que os mestrados profissionais com seus projetos formativos foram determinantes para centralidade dada ao foco temático em questão. Porém, isso não se deu em caráter de exclusividade, pois os mestrados acadêmicos também produziram pesquisas com esse foco temático. O Coletivo de Pesquisadores Educação em Ciências necessita realizar estudos mais cautelosos sobre o projeto formativo veiculado pelas resoluções que institucionalizaram o mestrado e o doutorado profissional para compreender melhor a natureza político-pedagógica dos elementos ativos do saber, frutos desses programas, que se agregam ao Estilo de Pensamento Educação em Ciências.

A implicação dos traços estilísticos apresentados até então é o de sinalizar para o Coletivo de Pesquisadores em Educação em Ciências a demanda de desenvolvimento de pesquisas sobre as atividades do Círculo Exotérico dos leigos (educandos da EJA), sobretudo, das que se ocupem da compreensão dos processos de aprendizagem dos conceitos científicos, utilizando para isso, referencial teórico marcado, seja ele qual for.

Este estudo trouxe uma contribuição, ao propor a tipificação denominada Produção Científica para a análise de focos temáticos em pesquisas do tipo Estado da Arte e/ou Estado do Conhecimento. Compreende-se, a partir da epistemologia fleckiana, que essa tipificação considera a própria atividade do Círculo Esotérico (especialistas) do Coletivo de Pesquisadores Educação em Ciências (CPEC), ou seja, a produção do conhecimento científico. Tem-se no Brasil pesquisas sobre o ensino de biologia (Slongo, 2004; Texeira, 2008), que se dedicaram a esse foco temático (Produção Científica). Contudo, no recorte do ensino de biologia na EJA, a análise da produção científica foi inaugurada por Araújo e Carneiro (2014), Porto e Teixeira (2014) e aprofundada por Paranhos (2017). Face a isso, aponta-se a necessidade de ampliar essa análise para a produção científica que toma o ensino física e química na EJA como objeto de investigação. Deste modo, um cenário mais amplo seria traçado em torno da atividade do CEso do CPEC que se ocupou do ensino de ciências (biologia, física e química) na Educação de Jovens e Adultos. 


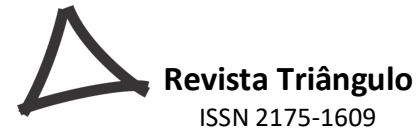

Este estudo considera relevante a necessidade de o Coletivo de Pesquisadores Educação em Ciências travar uma discussão sobre a natureza das contribuições de artigos do tipo Relato de Experiência para o desenvolvimento do Estilo de Pensamento Educação em Ciências. Ao ser veiculados por um legitimado meio do CPEC (periódicos), esses artigos portam ideias que se constituem em aspectos estilísticos do coletivo de pensamento, mesmo que a experiência vivida e relatada não seja pesquisa. A obviedade presente nessa afirmação necessita ser retomada no sentido de se constituir um aspecto formativo aos indivíduos que passarão pelos processos coercitivos de iniciação ao campo da Educação em Ciências.

Por fim, este estudo, aponta para o Coletivo de Pesquisadores Educação em Ciências uma interessante pauta investigativa a ser considerada pelo coletivo referente ao ensino de ciências na educação de jovens e adultos. Contudo, a compreensão da necessidade histórica da EJA em nosso país e a concepção de educação como direito devem ser tomados como o ponto de partida e de chegada das pesquisas sobre o ensino de ciências (biologia, física, química) na EJA.

\section{REFERÊNCIAS}

ARAÚJO, S. P.; CARNEIRO, M. H. S. Educação de jovens e adultos no ensino médio, uma revisão bibliográfica sobre o ensino de Ciências. Ciências \& Cognição, v. 19, n. 1, p. 96-104, 2014.

BRANDÃO, X. S. G. Uma análise da formação de professores de física do IFRN a partir da epistemologia de Ludwik Fleck. 2015. 148p. Dissertação (Mestrado em Educação). Centro de Educação, Universidade Federal do Rio Grande do Norte, Natal, RN.

BRASIL. Lei de Diretrizes e Bases da Educação Nacional. Lei número 9394, 20 de dezembro de 1996.

BRASIL. Ministério da Educação. Portaria n 389, de 23 de março de 2017. Dispõe sobre o mestrado e doutorado profissional no âmbito da pós-graduação strictu sensu. Diário Oficial da República Federativa do Brasil. Brasília, DF, 24 mar. 2017, seção 1, p. 61.

BRASIL. Ministério da Educação. Portaria normativa nº 17, de 28 de dezembro de 2009. Dispõe sobre o mestrado profissional no âmbito da Fundação Coordenação de Aperfeiçoamento de Pessoal de Nível Superior. Diário Oficial da República Federativa do Brasil. Brasília, DF, 28 dez. 2009, seção 1, p. 20.

CARNEIRO, J. A. C. A teoria comparativa do conhecimento de Ludwik Fleck: comunicabilidade e incomensurabilidade no desenvolvimento das ideias científicas. 2012. 194p. Dissertação (Mestrado em Filosofia). Faculdade de Filosofia, Letras e Ciências Humanas, Universidade de São Paulo, São Paulo, SP.

DELIZOICOV, D. et al. Sociogênese do conhecimento e pesquisa em ensino: contribuições a partir do referencial fleckiano. In: Encontro Nacional de Pesquisa em Educação em Ciências, 
2, 1999. Atas do II Encontro Nacional de Pesquisa em Educação em Ciências. Valinhos: NUTES-UFRJ, 1999. p.1-14.

DELIZOICOV, D. Pesquisa em ensino de ciências como ciências humanas aplicadas. Revista Brasileira de Ensino de Física, v. 21, p.145-175, ago., 2004.

DELIZOICOV, N. C. O movimento do sangue no corpo humano: história e ensino. 2002. 275p. Tese (Doutorado em Educação). Centro de Ciências da Educação, Universidade Federal de Santa Catarina, Florianópolis, SC.

FERREIRA, N. S. A. As pesquisas denominadas "estado da arte". Educação \& Sociedade, n. 79, p. 257-272, 2002.

FLECK, L. Genèse et développement d'un fait scientifique. Paris: Champs Sciences, 2008.

GAMBOA, S. S. Pesquisa em Educação: métodos e epistemologias. Chapecó: Argos, 2007.

LAMBACH, M.; MARQUES, C. A. Ensino de química na educação de jovens e adultos: relação entre estilos de pensamento e formação docente. Investigações em Ensino de Ciências, v. 14, n. 2, p. 219-135, 2009.

LAROCCA, P.; ROSSO, A. J.; SOUZA, A. P. A formulação dos objetivos de pesquisa na pós-graduação em Educação: uma discussão necessária. Revista Brasileira de PósGraduação, v. 2, n. 3, p. 118-133, 2005.

LORENZETTI, L. Estilo de pensamento em educação ambiental: uma análise a partir das dissertações e teses. Florianópolis - SC, 2008. 407f. Tese (Programa de Pós-Graduação em Educação Científica e Tecnológica). Universidade Federal de Santa Catarina.

MACHADO, M. M. O professor. In: HADDAD, S. (org.). Educação de jovens e adultos no Brasil (1986 - 1998). Brasília: MEC/Inep/Comped, 2002. p.25-46.

MEGID-NETO, J. M. Tendências da pesquisa acadêmica sobre o ensino de ciências no nível fundamental. 1999. 365p. Tese (Doutorado). Faculdade de Educação, Universidade Estadual de Campinas, Campinas, SP.

MUENCHEN, C.; DELIZOICOV, D. Pesquisas em educação em ciências na região de Santa Maria/RS: algumas características. In: Encontro Nacional de Pesquisa em Educação em Ciências, 7., 2009. Atas do VII Encontro Nacional de Pesquisa em Educação em Ciências. Florianópolis: NUTES-UFRJ, 2009. p.1-12.

OSTERMANN, F; REZENDE, F. Projetos de desenvolvimento e de pesquisa na área de ensino de ciências e matemática: uma reflexão sobre mestrados profissionais. Caderno Brasileiro de Ensino de Física, v. 26, n. 1, p. 66-80, 2009.

PARANHOS, R. D. Ensino de Biologia na Educação de Jovens e Adultos: o pensamento político-pedagógico da produção científica brasileira. Brasília - DF, 2017. 229f. Tese (Doutorado - Doutorado em Educação). Faculdade de Educação, Universidade de Brasília.

PARANHOS, R. D.; CARNEIRO, M. H. S. Ensino de biologia na educação de jovens e adultos: desafios para uma formação que proporcione o desenvolvimento humano. Rev. EJA em Debate, v. 8, n. 14, p. 1-24, jul./dez., 2019a.

PARANHOS, R. D.; CARNEIRO, M. H. S. Ensino de biologia na educação de jovens e adultos: distribuição da produção científica e aspectos que caracterizam o interesse intelectual de um coletivo de pesquisadores. Rev. Contexto \& Educação, v. 34, n. 108, p. 269-286, jun., $2019 b$.

PORTO, M. L. O.; TEIXEIRA, P. M. M. Ensino de biologia na Educação de Jovens e Adultos (EJA): um estudo de revisão bibliográfica. Revista da SBenBio, n. 7, p. 5437-5448, 2014 
ROMANOWSKI, J. P.; ENS, R. T. As pesquisas denominadas do tipo "estado da arte" em educação. Diálogo Educacional, v. 6, n. 19, p. 37-50, 2006.

SLONGO, I. I. P. A produção acadêmica em ensino de biologia: um estudo a partir de teses e dissertações. 2004. 360p. Tese (Doutorado em Educação). Centro de Ciências da Educação, Universidade Federal de Santa Catarina, Florianópolis, SC.

SLONGO, I. I. P.; DELIZOICOV, D. Um panorama da produção acadêmica em ensino de biologia desenvolvida em programas nacionais de pós-graduação. Investigações em Ensino de Ciências, v. 11, n. 3, dez., 2006.

SOUZA, A. C. Políticas públicas de educação de jovens e adultos. In: HADDAD, S. (org.). Educação de jovens e adultos no Brasil (1986 - 1998). Brasília: MEC/Inep/Comped, 2002. p.85-111.

TEIXEIRA, P. M. M. 35 anos da produção acadêmica em ensino de biologia no Brasil: catálogo analítico de dissertações e teses (1972-2006). Vitória da Conquista: Edições UESB, 2012.

TEIXEIRA, P. M. M. Pesquisa em ensino de biologia no Brasil [1972 - 2004]: um estudo baseado em dissertações e teses. 2008. 406. Tese (Doutorado em Educação). Faculdade de Educação, Universidade Estadual de Campinas, Campinas, SP. 